\title{
Gemmological samples: rock crystal from two localities in the Rhodopes, Bulgaria
}

\begin{abstract}
Stanislav Abadjiev
National Museum of Natural History, Bulgarian Academy of Sciences, 1 Tsar Osvoboditel Blvd, 1000 Sofia, Bulgaria, abadjiev@nmnhs.com

Abstract: The paper comprises gemmological and other data on several specimens of faceted rock crystal gemstones from two localities in the Madan ore field, Smolyan Province, and Krumovgrad Municipality, Kardzhali Province, of the Rhodopes, Bulgaria.
\end{abstract}

Keywords: gemstone, quartz, Rhodopes, rock crystal

\section{Introduction}

Quartz $\left(\mathrm{SiO}_{2}\right)$ is extraordinarily common mineral on Earth and occurs in a wide variety of rock types and geological environments. Fine specimens of its colourless crystalline variety, rock crystal, are known from many localities, especially in the USA, from Mount Ida, Montgomery County, Arkansas; Minas Gerais in Brazil; in the Alps of France, Switzerland, Italy, and Austria; Madagascar; Ural Mountains (Nether-Polar Urals) and elsewhere in Russia; Myanmar (Burma); Yamanashi Prefecture, Japan (Anthony et al., 20012005).

While studying the rich mineralogical holdings of the National Museum of Natural History at the Bulgarian Academy of Sciences, Sofia (NMNHS), Karov \& Dimitrov (2004: 9-10) list numerous localities and natural specimens of quartz and its varieties from different regions of Bulgaria, including many from the Rhodopes.

Rock crystal is frequently used in faceted gems, beads, carvings, and decorative objects. As a material for faceting, it has little intrinsic value, except in very large, flawless pieces. It can be of enormous size, as illustrated by the more than $32 \mathrm{~cm}$ in diameter, 48.5 $\mathrm{kg}$ perfect sphere of flawless Burmese material in the National Museum of Natural History, Smithsonian Institution, Washington, DC, the largest fine crystal ball in the world. There are faceted specimens of 7000 carats recorded (Arem, 1987: 158-159).

Faceted specimens of rock crystal or any crystalline quartz from Bulgaria, however, remain a certain rarity.

\section{Results}

The specimen factual information listed here includes identifier (hyperlinked to its repository web page at National Museum of Natural History's online database, nmnhs.com/gemmology), shape, weight, clarity, design, georeferenced locality, rough origin, and is as follows: 0206 (Fig. 1) hexagon, $0.51 \mathrm{ct}$, eye clean, design "Hexamixtum S 42-43"; 0420 (Fig. 2) oval, 0.47 ct, eye clean, design "Ovalimixtum"; 0616 (Fig. 3) octagon, $5.70 \mathrm{ct}$, eye clean, mixed style cut, faceted by Multicolour Gems Ltd, Bangkok, Thailand; additional specimen with similar data exist in the NMNHS collection; 0680 (Fig. 4) hexagon, 0.13 ct, eye clean, design "Hexamixtum S 41-32" [pavilion angle changed to 45']; 0709 (Fig. 5) hexagon, 0.27 ct, eye clean, same design [crown angle changed to 38ㄱ); 0755 (Fig. 6) octagon, 0.51 ct, eye clean, design "Petal" by Glenn \& Martha Vargas; 0762 octagon, $0.46 \mathrm{ct}$, slightly included, same design; locality for 0206, 0420, 0616, 0755, 0762 - Bulgaria, Smolyan 

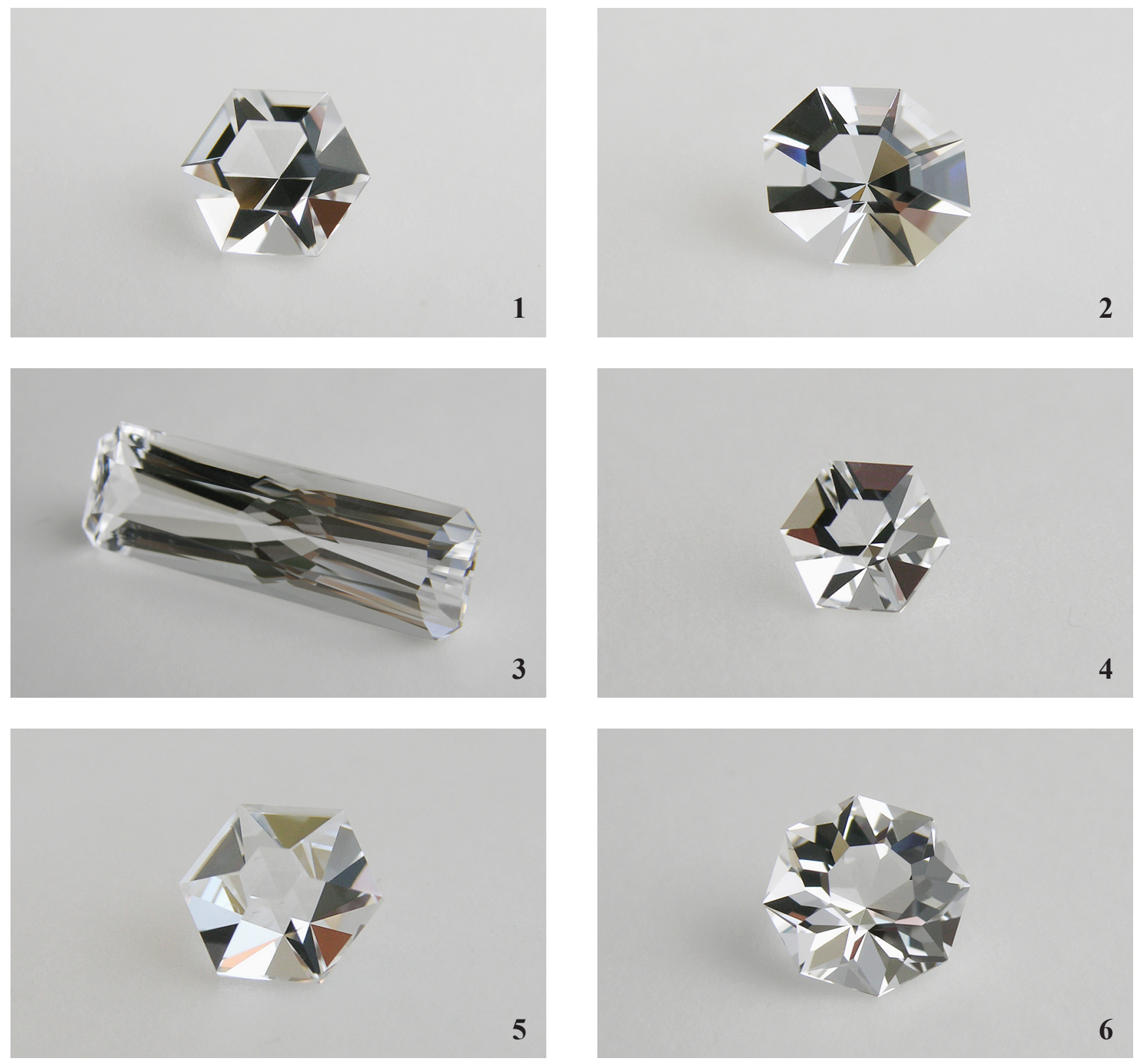

Figs 1-6. Faceted samples of rock crystal: (1-3, 6) Krushev Dol Pb-Zn deposit; (4, 5) Yaraklitepe.

Province, Madan Municipality, Rhodope Mountains, Krushev Dol $\mathrm{Pb}-\mathrm{Zn}$ deposit, $41.44577^{\circ} \mathrm{N} 24.93477^{\circ} \mathrm{E}$ (Fig. 7: point 1), rough obtained from Mr Shukri Sirakov, Madan; locality for 0680 and 0709 - Bulgaria, Kardzhali Province, Krumovgrad Municipality, East Rhodope Mountains, Yaraklitepe, $41.50262^{\circ} \mathrm{N}$ 25.644925 $5^{\circ}$ (Fig. 7: point 2), $444 \mathrm{~m}$, rough collected by the author; specimens 0206, 0420, 0680, 0709, 0755,0762 have been cut by the author.

The crystalline quartz, especially rock crystal, is common in the mines of the Madan ore field and is often associated with calcite $\left(\mathrm{CaCO}_{3}\right)$, chalcopyrite $\left(\mathrm{CuFeS}_{2}\right)$, galena $(\mathrm{PbS})$, pyrite $\left(\mathrm{FeS}_{2}\right)$, sphalerite $(\mathrm{ZnS})$. Five generations of crystal growth have been identified there (Petrussenko, 1991: 444). It should be noted that the Madan ore field is a large lead-zinc mining district, known since ancient times, exploited in the Middle Ages and extensively mined during the last two centuries in more than 40 underground mines. Madan mines produce one of the finest quartz crystals in Bulgaria. In the East Rhodope Mountains, in the valley of Arda River and the nearby areas a cryp- 


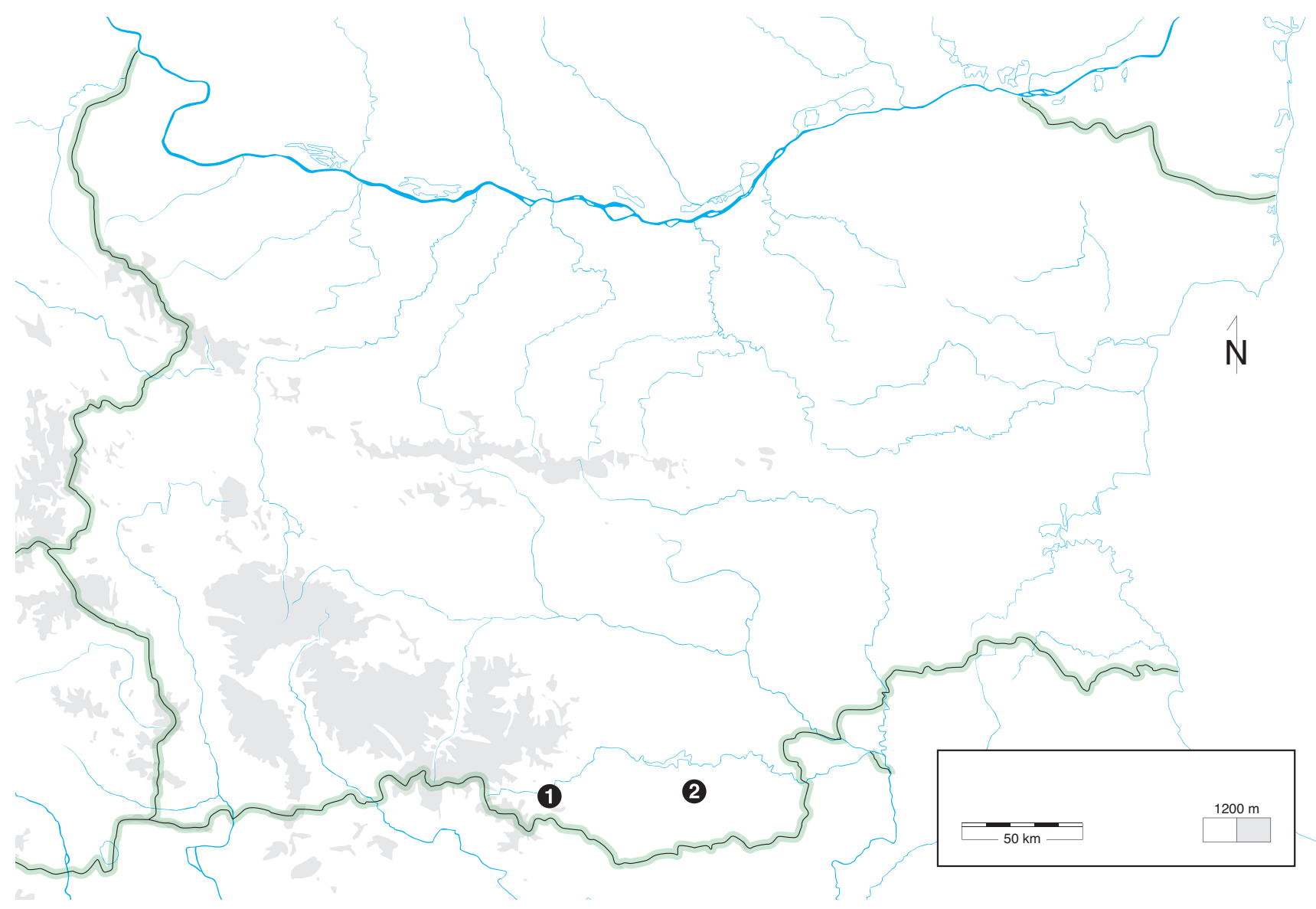

Fig. 7. Map of Bulgaria with localities of rock crystal gem specimens studied: (point 1) Krushev Dol Pb-Zn deposit; (point 2) Yaraklitepe.

tocrystalline variety chalcedony prevails, whereas crystalline samples are relatively rarely found in very small crystals in specific geodes (Tsintsov \& Banushev, 2010) and are generally not suitable for faceting.

The majority of the gemstones were cut on electronically modified variant of Xristal-tek " 87 " faceting machine by Poly-Metric Instruments, Inc., Clayton, WA, USA, using diamond coated flat laps of different grits $(320,600,1200)$ by THK Diamond Tools, Hong Kong, and polished using a DARKSIDETM lap (Gearloose Lapidary, LLC, North Easton, MA, USA), charged with zirconium dioxide BATTSTIK ${ }^{\mathrm{TM}}$ (Gearloose Lapidary, LLC) or cerium(IV) oxide powder mixed with distilled or low mineralisation water.

In four specimens the following original author's designs have been used: "Hexamixtum S 41-32" (specimens 0680, 0709) - brilliant style cut, hexagonal shape, 6-fold radial symmetry, 19 facets; in both cases original pavilion or crown angle changed to save weight; "Hexamixtum S 42-43" (specimen
0206) - brilliant style cut, hexagonal shape, 6-fold radial symmetry, 19 facets; "Ovalimixtum" (specimen 0420) - mixed style cut, oval shape, 2-fold mirror-image symmetry, 33 facets. All of these were designed using Gem Cut Studio (version 1.0.0) with angles for refractive index 1.54, close to that of quartz.

Some faceted samples from Krushev Dol $\mathrm{Pb}-\mathrm{Zn}$ deposit contain tiny cavities or negative crystals with bubbles and other inclusions. They are generally very clean. These from Yaraklitepe are cleaner, but substantially smaller. In both cases, such a clarity can be considered natural, because crystal parts with inclusions are usually removed during the faceting process.

\section{Acknowledgments}

Special thanks to Mr David Weinberg of Multicolour Gems Ltd, who kindly arranged faceting the initial specimens in their facility in Bangkok, Thailand. I am 
very much obliged to Associate Professor Svetoslav Petrussenko, Sofia for his valuable suggestions and corrections.

\section{References}

Anthony J.W., Bideaux R.A., Bladh K.W., Nichols M.C. (eds) 2001-2005 Quartz. Handbook of Mineralogy. Mineralogical Society of America, Chantilly, VA, handbookofmineralogy.org.

Arem J.E. 1987 Color encyclopedia of gemstones. 2nd edition. Springer, Boston, 248 pp.
Karov C., Dimitrov I. 2004 A catalogue of the mineral species in the National Museum of Natural History, Sofia (Part 2) Silicates. Historia naturalis bulgarica 16: 7-45.

Petrussenko S. 1991 Minerals of the Madan orefield, Bulgaria. The Mineralogical Record 22 (6): 439445.

Tsintsov Z., Banushev B. 2010 Agates in Bulgaria. "Stiluet" Ltd, Publishing House "Vanio Nedkov", Sofia, 210 pp. (In Bulgarian) 